\title{
Performance of the revised ' 175 ' Modification of Diet in Renal Disease equation in patients with type 2 diabetes
}

\author{
R. A. Chudleigh $\cdot$ R. L. Ollerton • G. Dunseath • \\ R. Peter • J. N. Harvey $\cdot$ S. Luzio • D. R. Owens
}

Received: 18 March 2008 / Accepted: 22 May 2008 /Published online: 17 July 2008

(C) Springer-Verlag 2008

\begin{abstract}
Aims/hypothesis Estimation of GFR (eGFR) is recommended for the assessment of kidney function in all patients with diabetes. We studied performance of the traditional '186' Modification of Diet in Renal Disease (MDRD) equation, and the 2005 revised ' 175 ' MDRD equation in patients with type 2 diabetes.

Methods Two hundred and ninety-three mainly normoalbuminuric (267/293) patients were recruited. Patients were classified as having mild renal impairment (group 1, GFR $<90 \mathrm{ml} \mathrm{min}-1.73 \mathrm{~m}^{-2}$ ) or normal renal function (group 2, GFR $\geq 90 \mathrm{ml} \mathrm{min}^{-1} 1.73 \mathrm{~m}^{-2}$ ). eGFR was calculated by the traditional 186 MDRD equation using traditional creatinine values and the revised 175 MDRD equation using isotope dilution mass spectrometry-standardised creatinine values. Isotopic GFR was measured by the four-sample plasma clearance of ${ }^{51} \mathrm{Cr}$-EDTA.

Results For patients in group 1, mean $\pm \mathrm{SD}$ isotopic ${ }^{51} \mathrm{Cr}$ EDTA GFR (iGFR) was $83.8 \pm 4.3 \mathrm{ml} \mathrm{min}^{-1} 1.73 \mathrm{~m}^{-2}$, and eGFR was $73.2 \pm 11.9$ and $75.8 \pm 13.7 \mathrm{ml} \mathrm{min}^{-1} 1.73 \mathrm{~m}^{-2}$
\end{abstract}

R. A. Chudleigh $(\bowtie) \cdot$ G. Dunseath $\cdot$ R. Peter $\cdot$ S. Luzio $\cdot$

D. R. Owens

Diabetes Research Unit, Llandough Hospital,

Penlan Road,

Llandough, Penarth CF64 2XX, UK

e-mail: rachudleigh@hotmail.com

R. L. Ollerton

School of Computing and Mathematics,

University of Western Sydney,

Penrith South DC, NSW, Australia

J. N. Harvey

Department of Medicine, Wrexham Maelor Hospital,

Wrexham, UK using the 186 and 175 MDRD equations, respectively. Method bias was -10.6 with the $186 \mathrm{MDRD}$ and $-7.9 \mathrm{ml} \mathrm{\textrm {min } ^ { - 1 }}$ $1.73 \mathrm{~m}^{-2}(p<0.05)$ with the $175 \mathrm{MDRD}$ equation. In group 2, iGFR was $119.4 \pm 20.2 \mathrm{ml} \mathrm{min}^{-1} 1.73 \mathrm{~m}^{-2}$, and eGFR was $92.3 \pm 18.6$ and $97.5 \pm 21.6 \mathrm{ml} \mathrm{min}^{-1} 1.73 \mathrm{~m}^{-2}$ using the 186 and 175 MDRD equations, respectively. Method bias was -27.1 with the 186 MDRD equation and $-21.9 \mathrm{ml} \mathrm{min}^{-1}$ $1.73 \mathrm{~m}^{-2}(p<0.05)$ with the 175 MDRD equation.

Conclusions/interpretation In patients newly diagnosed with type 2 diabetes, the revised 175 MDRD equation was less biased than the traditional 186 MDRD equation. Despite a continued tendency to underestimate isotopically measured GFR, use of standardised creatinine values is a positive step towards improved estimation of GFR.

Keywords eGFR · 175 MDRD equation · Standardised creatinine · Type 2 diabetes

Abbreviations
$\begin{array}{ll}\text { CKD } & \text { chronic kidney disease } \\ { }^{51} \text { Cr-EDTA } & { }^{51} \text { Cr-labelled EDTA } \\ \text { eGFR } & \text { estimation of GFR } \\ \text { IDMS } & \text { isotope dilution mass spectrometry } \\ \text { iGFR } & \text { isotopic }{ }^{51} \text { Cr-labelled EDTA GFR } \\ \text { MDRD } & \text { Modification of Diet in Renal Disease }\end{array}$

\section{Introduction}

Current recommendations suggest that all persons with diabetes have annual creatinine-based estimation of GFR (eGFR) and measurement of AER.

The National Kidney Foundation recommends the Modification of Diet in Renal Disease (MDRD) equation for calculation of eGFR $[1,2]$. This equation is more 
readily calculated and provides a better estimate of true GFR in patients with chronic kidney disease (CKD).

However, in patients free of CKD the MDRD equation poorly estimates GFR [3]. Serum creatinine is a critical variable for MDRD-calculated eGFR. Currently great interlaboratory variability exists in the measurement and calibration of creatinine $[4,5]$. This variability introduces error into GFR estimates, which has greatest impact at creatinine concentrations within the normal range; this is particularly important when attempting to detect early decline in GFR [4].

To implement eGFR universally, an effort to standardise creatinine measurement is being made by the National Kidney Disease Education Programme [6]. Isotope dilution mass spectrometry (IDMS) is considered the gold standard for establishing true creatinine concentration [6]. This programme aims to ensure that creatinine values are traceable to an IDMS reference value in order that creatinine measurements are comparable regardless of method or laboratory used.

IDMS creatinine values are up to $20 \%$ lower than creatinine values obtained by the alkaline picrate method [6]. Consequently, the MDRD equation was re-expressed for use with IDMS creatinine values [7].

We compared performance of the original ' 186 ' MDRD equation using non-standardised creatinine values and the revised ' 175 ' MDRD equation using IDMS-traceable creatinine to estimate isotopic ${ }^{51} \mathrm{Cr}$-labelled EDTA $\left({ }^{51} \mathrm{Cr}\right.$ EDTA)-measured GFR (iGFR) in patients newly diagnosed with type 2 diabetes.

\section{Methods}

Patients We studied 293 patients with newly diagnosed type 2 diabetes who had a reference iGFR measurement and sufficient clinical and biochemical data.

Diagnosis was made by the criteria set by the WHO at time of recruitment [8]. Ninety-six per cent (282/293) of patients were white, the remainder being of South Asian origin. None was of African-American origin.

Clinical methods Following an overnight fast, anthropometric and biochemical measurements were made. Patients were intravenously cannulated and blood samples drawn. Subsequently, $1 \mathrm{MBq}{ }^{51} \mathrm{Cr}$-EDTA was administered at 0 min, with further blood sampling at 44, 120, 180 and $240 \mathrm{~min}$.

Laboratory methods The ${ }^{51} \mathrm{Cr}$-EDTA plasma clearance method for GFR measurement was corrected for body surface area. The four-sample method allowed estimation using a two-compartment model.
Serum creatinine measurement Creatinine levels were determined using the OCD dry-slide system on the Vitros $750 \mathrm{X} \mathrm{RC}$ and 950 analyser (HP12 4DP; Johnson \& Johnson, High Wycombe, UK). The CV the assay was $4.2 \%$ at a creatinine concentration of $103 \mu \mathrm{mol} / \mathrm{l}$ and $1.92 \%$ at a creatinine concentration of $516 \mu \mathrm{mol} / \mathrm{l}$. Creatinine measurement was validated by the Welsh External Quality Assurance Scheme.

IDMS creatinine calculation IDMS-traceable creatinine values were obtained according to the recommendations of the UK National External Quality Assessment Service for the OCD dry-slide method [9]:

IDMS creatinine $(\mu \mathrm{mol} / \mathrm{l})=$

$$
\text { [serum creatinine }(\mu \mathrm{mol} / \mathrm{l})-7.71] / 0.988
$$

Estimation of GFR GFR was estimated using the original four-variable 186 MDRD equation [2] with unadjusted serum creatinine values and the revised four-variable 175 MDRD formula [7] using IDMS-traceable creatinine values, as recommended by the National Kidney Disease Education Programme [6]. These formulas are shown below.

The abbreviated four-variable 186 MDRD formula [2]:

$\operatorname{eGFR}\left(\mathrm{ml} \mathrm{min}^{-1} 1.73 \mathrm{~m}^{-2}\right)=186 \times$

[serum creatinine $(\mu \mathrm{mol} / 1) / 88.4]^{-1.154} \times$

$[\text { age }(\text { years })]^{-0.203} \times[0.742$ if female $] \times$

[1.210 if African American]

The revised four-variable 175 MDRD formula [7]:

$$
\begin{aligned}
& \operatorname{eGFR}\left(\mathrm{ml} \mathrm{min}^{-1} 1.73 \mathrm{~m}^{-2}\right)=175 \times \\
& {[\text { IDMS creatinine }(\mu \mathrm{mol} / 1) / 88.4]^{-1.154} \times} \\
& {[\text { age }(\text { years })]^{-0.203} \times[0.742 \text { if female }] \times} \\
& {[1.210 \text { if African American }]}
\end{aligned}
$$

Statistical analysis Data were assessed graphically for serial correlation. Patients were grouped by iGFR in keeping with National Kidney Foundation CKD stage [1], group 1 having iGFR $60-89 \mathrm{ml} \mathrm{min}-11.73 \mathrm{~m}^{-2}$ and group 2 having iGFR $\geq 90 \mathrm{ml} \mathrm{min}^{-1} 1.73 \mathrm{~m}^{-2}$. Data were analysed using two-tailed paired and unpaired $t$ tests as appropriate (confirmed by non-parametric equivalents for non-normal distributions), $\chi^{2}$ test for proportions, and linear regression. Regression, goodness-of-fit and other statistical method assumptions were checked graphically and by use of relevant statistics. All calculations were performed using SPSS 
Table 1 Demographic data

\begin{tabular}{llll}
\hline Variable & All patients & $\begin{array}{l}\text { Group 1 } \\
\left(\mathrm{GFR}<90 \mathrm{ml} \mathrm{min}^{-1} 1.73 \mathrm{~m}^{-2}\right)\end{array}$ & $\begin{array}{l}\text { Group 2 } \\
\left(\mathrm{GFR} \geq 90 \mathrm{ml} \mathrm{min}^{-1} 1.73 \mathrm{~m}^{-2}\right)\end{array}$ \\
\hline$n$ & & 37 & 256 \\
Male/female & 293 & $25 / 12$ & $196 / 60$ \\
Age $($ years $)$ & $221 / 72$ & $62.2 \pm 6.8$ & $54.1 \pm 9.3 *$ \\
Weight $(\mathrm{kg})$ & $55.2 \pm 9.4$ & $88.0 \pm 16.7$ & $92.5 \pm 17.0$ \\
BMI $\left(\mathrm{kg} / \mathrm{m}^{2}\right)$ & $91.9 \pm 17.0$ & $30.9 \pm 6.0$ & $31.6 \pm 5.5$ \\
Fasting plasma glucose $(\mathrm{mmol} / \mathrm{l})$ & $31.5 \pm 5.6$ & $8.45 \pm 2.9$ & $9.88 \pm 3.1 *$ \\
HbA $(\%)$ & $9.67 \pm 3.0$ & $7.16 \pm 1.83$ & $7.88 \pm 2.01^{*}$ \\
Systolic BP $(\mathrm{mm} \mathrm{Hg})$ & $7.79 \pm 2.00$ & $144 \pm 22$ & $135 \pm 19^{*}$ \\
Diastolic BP $(\mathrm{mm} \mathrm{Hg})$ & $136 \pm 20$ & $80 \pm 10$ & $82 \pm 10$ \\
Creatinine $(\mu \mathrm{mol} / \mathrm{l})$ & $81 \pm 10$ & $90.7 \pm 16.1$ & $78.4 \pm 13.9 *$ \\
IDMS creatinine $(\mu \mathrm{mol} / \mathrm{l})$ & $80.0 \pm 14.8$ & $83.8 \pm 16.3$ & $71.4 \pm 14.0^{*}$ \\
GFR $\left(\mathrm{ml} \mathrm{min}{ }^{-1} 1.73 \mathrm{~m}^{-2}\right)$ & $73.0 \pm 14.9$ & $83.8 \pm 4.3$ & $119.4 \pm 20.2^{*}$ \\
\hline
\end{tabular}

Data are means $\pm \mathrm{SD}$

$* p<0.05$ for difference between means of group 1 and group 2

(12.0.1, SPSS 2003) software package. Results are presented as mean $\pm \mathrm{SD}$ and $95 \%$ CIs unless otherwise indicated. $p<0.05$ was taken to indicate statistical significance.

\section{Results}

Demographic characteristics of study participants are summarised in Table 1. Ninety-one per cent of participants were normoalbuminuric. IDMS creatinine values were significantly lower than non-IDMS creatinine values in both groups and by approximately $10 \%$ overall. Table 1 shows that patients in group 1 (iGFR $<90 \mathrm{ml} \mathrm{min}^{-1} 1.73 \mathrm{~m}^{-2}$ ) were on average older with greater non-IDMS and IDMStraceable serum creatinine concentrations than those in group 2. Conversely, group 2 patients had greater $\mathrm{HbA}_{1 \mathrm{c}}$ and fasting plasma glucose concentrations. There was no significant inter-group difference in weight or BMI.

Performance of the 186 and 175 MDRD formula-derived eGFR is presented in Table 2. Performance was assessed by

Table 2 Performance of GFR estimation equations

\begin{tabular}{|c|c|c|c|c|c|c|}
\hline & \multicolumn{2}{|c|}{$\begin{array}{l}\text { All patients } \\
\left(\text { iGFR } 114.9 \pm 22.4 \mathrm{ml} \mathrm{min}^{-1} 1.73 \mathrm{~m}^{-2} \text { ) }\right.\end{array}$} & \multicolumn{2}{|c|}{$\begin{array}{l}\text { Group } 1 \\
\left(\text { iGFR } 83.8 \pm 4.3 \mathrm{ml} \mathrm{min}^{-1} 1.73 \mathrm{~m}^{-2}\right)^{\mathrm{a}}\end{array}$} & \multicolumn{2}{|c|}{$\begin{array}{l}\text { Group } 2 \\
\left(\text { iGFR } 119.4 \pm 20.2 \mathrm{ml} \mathrm{min}^{-1}\right. \\
\left.1.73 \mathrm{~m}^{-2}\right)^{\mathrm{a}}\end{array}$} \\
\hline & $186 \mathrm{MDRD}$ & 175 MDRD & 186 MDRD & 175 MDRD & $186 \mathrm{MDRD}$ & 175 MDRD \\
\hline 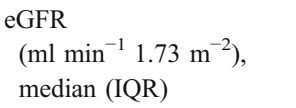 & $\begin{array}{l}89.9 \pm 19.0 \\
(87.0 \pm 25.0)\end{array}$ & $\begin{array}{l}94.7 \pm 22.0 * \\
(91.0 \pm 29.0)\end{array}$ & $\begin{array}{l}73.2 \pm 11.9 \\
(73.0 \pm 18.0)\end{array}$ & $\begin{array}{l}75.8 \pm 13.7 * \\
(75.0 \pm 20.0)\end{array}$ & $\begin{array}{l}92.3 \pm 18.6 \\
(89.0 \pm 24.8)\end{array}$ & $\begin{array}{l}97.5 \pm 21.6^{*} \\
(94.0 \pm 29.8)\end{array}$ \\
\hline Bias $\left(\mathrm{ml} \mathrm{min}-1.73 \mathrm{~m}^{-2}\right)$ & $\begin{array}{l}-25.0 \\
(-26.9,-23.1)\end{array}$ & $\begin{array}{l}-20.1^{*} \\
(-22.1,-18.1)\end{array}$ & $\begin{array}{l}-10.6 \\
(-14.3,-6.8)\end{array}$ & $\begin{array}{l}-7.9 * \\
\quad(-12.2,-3.7)\end{array}$ & $\begin{array}{l}-27.1 \\
(-29.0,-25.1)\end{array}$ & $\begin{array}{l}-21.9 * \\
(-24.0,-19.7)\end{array}$ \\
\hline Precision & 16.6 & 17.6 & 11.2 & 12.8 & 16.2 & 17.5 \\
\hline Accuracy 10\% (\%) & $15(11,19)$ & $22 *(16,26)$ & $30(14,45)$ & $43(26,60)$ & $13(9,17)$ & $18 *(14,23)$ \\
\hline Accuracy 30\% (\%) & $79(74,84)$ & $86^{*}(82,90)$ & $95(87,100)$ & $95(87,100)$ & $77(71,82)$ & $84 *(80,89)$ \\
\hline$r$ & 0.689 & 0.685 & 0.349 & 0.348 & 0.654 & 0.651 \\
\hline$r^{2}$ & 0.475 & 0.469 & 0.122 & 0.121 & 0.428 & 0.424 \\
\hline Gradient & $0.81(0.71,0.91)$ & $0.70(0.61,0.78)$ & $0.126(0.01,0.24)$ & $0.110(0.01,0.21)$ & $0.71(0.61,0.81)$ & $0.609(0.52,0.70)$ \\
\hline Intercept & $41.9(32.9,51.0)$ & $49.0(40.6,57.3)$ & $74.5(66.0,83.2)$ & $75.4(67.6,83.3)$ & $53.8(44.2,63.3)$ & $60.0(51.3,68.8)$ \\
\hline
\end{tabular}

Data are means $\pm \mathrm{SD}$ or $(95 \% \mathrm{CI})$ unless otherwise indicated

Bias (mean difference between eGFR and iGFR), precision (SD of the bias), 95\% limits of agreement of eGFR and iGFR, accuracy (proportion of eGFR values within $10 \%$ and $30 \%$ of iGFR), $r^{2}$ (proportion of variability explained by the linear relationship) and linear regression gradient and intercept values of eGFR vs iGFR are shown

$I Q R$ interquartile range

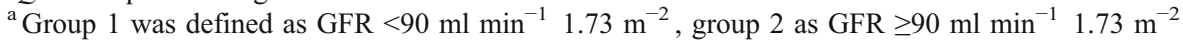

$* p<0.05$ for difference between means calculated by 186 and 175 MDRD equations

All $r$ values were significantly different from zero 
use of bias (mean of the difference between eGFR and iGFR), precision (SD of bias), accuracy (proportion of eGFR results within 10 and $30 \%$ of iGFR), linear regression $\left(r^{2}\right.$ values, regression equation, gradient and intercept values for iGFR vs eGFR).

Values for bias show that both formulas significantly underestimate iGFR; however, bias is significantly smaller using the 175 MDRD equation in both groups. Significant improvements in accuracy within $10 \%$ and $30 \%$ are seen using the 175 MDRD equation in the group as a whole and specifically in group 2. A trend towards improved accuracy in group 1 failed to achieve statistical significance.

\section{Discussion}

MDRD-derived eGFR is advocated for assessment of kidney function in patients with diabetes [1]. Although validated in CKD [2], it has recognised limitations outside of this setting. Underestimation of higher GFR levels with overestimation of CKD has been observed [3]. Underestimation of iGFR has been attributed to inaccuracies of measurement, and greater variability in creatinine concentration due to non-renal factors in patients without CKD [4-6].

In this study, IDMS creatinine values were significantly lower than traditional creatinine values. Both formulas introduced significant biases and tended to underestimate GFR. This being most pronounced applying the 186 MDRD formula to patients with iGFR $\geq 90 \mathrm{ml} \mathrm{m^{-1 }} 1.73 \mathrm{~m}^{-2}$.

This finding contrasts with those of Froissart [10], who demonstrated a bias of $-6.2 \mathrm{ml} \mathrm{min}^{-1} 1.73 \mathrm{~m}^{-2}$ in a subgroup of 482 European patients with CKD and GFR $>90 \mathrm{ml}$ $\min ^{-1} 1.73 \mathrm{~m}^{-2}$. The difference may partly be explained by the fact that our patients were newly diagnosed with type 2 diabetes, many being obese, both factors being known to be associated with hyperfiltration.

We recognise that underestimation may be partly attributable to creatinine values not being calibrated to those of the MDRD laboratory. However, the MDRD equation was also derived using GFR measured by the urinary clearance of ${ }^{125}$ I-labelled iothalamate rather than ${ }^{51}$ Cr-EDTA clearance; it does not specify that identical methods of creatinine measurement are required for its use and our findings represent current clinical practice.

Use of IDMS-traceable creatinine values with the 175 MDRD equation partially improved performance of the equation in terms of both bias and accuracy, in the group described. IDMS creatinine values were derived using recognised formulas, which, pending widespread implementation of IDMS-traceable creatinine measurements, again reflects current clinical practice. Evidence that this transformation improves performance is encouraging.
The lower bias observed with the 175 MDRD equation was statistically significant in all subgroups of the study. Furthermore, statistically significant improvements in accuracy of estimation within $10 \%$ and $30 \%$ of isotopic GFR were observed when the group was studied as a whole, and in patients from group 2. Improved accuracy was also seen in group 1, although this failed to reach statistical significance, possibly due to the small number studied. Precision of equations was unchanged using the 175 equation compared with the 186 MDRD, although improved precision was seen with decline in iGFR.

Overall, use of IDMS-traceable creatinine in the revised 175 MDRD equation did slightly improve estimation of iGFR in patients with diabetes. We conclude that universal standardisation of creatinine measurement will improve the ability of the MDRD equation to detect early changes in GFR.

However, despite improvements in accuracy of creatinine measurement, plasma creatinine concentrations will fluctuate according to non-renal factors such as diet, exercise and BP. This will influence eGFR results, especially when creatinine values are within the normal reference range [4].

The variability of eGFR is illustrated in our study of mainly white normoalbuminuric patients, where significant underestimation of iGFR remained despite use of IDMS creatinine values and the revised MDRD equation.

While efforts are being made to generate equations which more accurately reflect GFR in diabetes, standardised creatinine values are a positive step towards improved eGFR.

Use of eGFR for assessment of kidney function in patients with diabetes is now established. Our data show that use of IDMS-standardised creatinine improves the overall performance of the MDRD equation; however, significant underestimation of iGFR continues to occur in this patient group.

Duality of interest The authors declare that there is no duality of interest associated with this manuscript.

\section{References}

1. The National Kidney Foundation Kidney Disease Outcomes Quality Initiative (NKF KDOQI). Diabetes and chronic kidney disease. Available from http://www.kidney.org/professionals/ KDOQI/, accessed 2 August 2007

2. Levey AS, Bosch JP, Lewis JB, Greene T, Rogers N, Roth D (1999) A more accurate method to estimate glomerular filtration rate from serum creatinine: a new prediction equation: Modification of Diet in Renal Disease Study Group. Ann Intern Med 130:461-470

3. Rossing P, Rossing K, Gaede P, Pedersen O, Parving HH (2006) Monitoring kidney function in type 2 diabetic patients with incipient and overt diabetic nephropathy. Diabetes Care 29:1024-1030

4. Coresh J, Astor BC, McQuillan G et al (2002) Calibration and random variation of the serum creatinine assay as critical elements 
of using equations to estimate the glomerular filtration rate. Am J Kidney Dis 39:920-929

5. Murthy K, Stevens LA, Stark PC, Levey AS (2005) Variation in serum creatinine assay calibration: a practical application to glomerular filtration rate estimation. Kidney Int 68:1884-1887

6. Myers GL, Miller WG, Coresh J et al (2006) Recommendations for improving serum creatinine measurement: a report from the Laboratory Working Group of the National Kidney Disease Education Program. Clin Chem 52:5-18

7. Levey AS, Coresh J, Greene T et al (2006) Chronic Kidney Disease Epidemiology Collaboration: using standardized serum creatinine values in the modification of diet in renal disease study equation for estimating glomerular filtration rate. Ann Intern Med 145:247-254

8. Alberti KGMM, Zimmett PZ for the WHO Consultation (1998) Definition, diagnosis and classification of diabetes mellitus and its complications. Part 1: diagnosis and classification of diabetes mellitus. Provisional report of a WHO Consultation. Diabet Med 15:539-553

9. UKNEQAS eGFR slope adjustor. Available from http://www. ukneqas.org.uk, accessed 14 August 2007

10. Froissart M, Rossert J, Jacquot C, Paillard M, Houillier P (2005) Predictive performance of the modification of diet in renal disease and Cockcroft-Gault equations for estimating renal function. J Am Soc Nephrol 16:763-773 